\title{
The Management of Major Depressive Disorder in Primary Care
}

\section{Birinci Basamakta Major Depresif Bozukluğa Yaklaşım}

\author{
Bektaş Murat Yalçın ${ }^{1}$, Onur Öztürk ${ }^{2}$
}

\begin{abstract}
Depression is may be the most important psychiatric disease for primary care health professionals. Depression is a mood disorder in which the individual always feel sad, melancholic or depressed without a reason, accompanying feelings of a deep distress, unworthiness, powerless, unwillingness, a negative view for life with impaired or slowed speech, motion and some physiological functions. World Health Organization had declared that unipolar major depression is the fifth leading most important health problem around the world in 1990, by the 2020 it will the second ranking health problem just under the ischemic cardiovascular diseases. Mood disorders can be categorized basically as depressive (unipolar) and manic depressive (bipolar) into two and diagnosed with DSM-V-TR criteria. In this condition to aware of depressed patients (search), to diagnose, to differentiate between primary and secondary mood disorders, to start an antidepressant therapy if necessary and consult the success of the therapy and to refer the patient to another health center in necessary conditions can be accounted as the principle duties of the primary care physicians. The aim of this review is to provide the latest knowledge for primary care physicians while managing depression.
\end{abstract}

Key words: Depression, primary care, management

\section{ÖZET}

Depresyon, birinci basamak sağlık hizmetlerinde çalışanlar için belki de en önemli psikiyatrik hastalıktır. Depresyon, belirli bir nedeni olmadan bireyin kendini sürekli üzüntülü, melankolik veya kederli hissetmesi, bu duruma yoğun bir bunaltı, değersizlik, güçsüzlük, isteksizlik, olumsuz bir bakış açısı gibi duyguların eşlik ettiği, ayrıca beraberinde düşünce, konuşma, devinim ve bazı fizyolojik işlevlerde yavaşlamanın gözlendiği bir duygu durum bozukluğudur. Dünya Sağlık Örgütü, 1990 yılında unipolar majör depresyonu dünyada en sık izlenen beşinci önemli sağlık sorunu olduğunu bildirirken, 2020 y1lında iskemik kalp hastalıklarından sonra en önemli ikinci sağlık sorunu olacağını tahmin etmektedir. Duygu durum bozuklukları, depresif (unipolar) ve manik depresif (bipolar) olarak temelde ikiye ayrılır ve tanısı DSM-V-TR kriterlerince konulur. Bu durumda birinci basamak hekiminin temel görevi, duygu durum bozukluğuna sahip hastalarını ayırt etmek (taramak), tanı koymak, birincil ve ikincil duygu durum bozukları arasında tanısal ayrımı yapabilmek, gerekse antidepresan tedaviye başlayarak bu tedavinin etkinliğini gözlemek ve gerekli hallerde hastayı bir başka merkeze yönlendirmektir. Bu derlemenin amacı, birinci basamak hekimlerinin depresyon yönetimi sırasında ortaya koyacakları yaklaşım için gerekli olan güncel bilginin sağlanmasıdır.

Anahtar kelimeler: Depresyon, birinci basamak, yaklaşım

Received / Geliş tarihi: 09.04.2016, Accepted / Kabul tarihi: 09.09.2016

${ }^{1}$ Ondokuz Mayıs Üniversitesi Tıp Fakültesi Aile Hekimliği Anabilim Dalı

${ }^{2}$ Asarcık Meydan Aile Sağlı̆̆ı Merkezi

*Address for Correspondence / Yazışma Adresi: Onur Öztürk, Asarcık Meydan Aile Sağlığı Merkezi, Samsun-TÜRKIYE, E-mail: dr.onurozturk@yahoo.com

Yalçın BM, Öztürk O. Birinci Basamakta Major Depresif Bozukluğa Yaklaşım. TJFMPC, 2016;10(4): 250-258.

DOI: $10.21763 / \mathrm{tjfmpc} .271331$ 


\section{GíRIŞ}

Genel nüfusta, psikiyatrik rahatsızlıklar açısından yaşam kalitesini artırmak için, toplum temelli ruh sağlığı hizmet modeli ilk kez 1978 Alma-Ata Bildirgesi ile vurgulanmış ${ }^{1}$ ve ruh sağlığ1 hizmetlerinin birincil bakıma bütünleștirilmesi önerilmiştir. 2008 yılında Dünya Sağlık Örgütü (DSÖ) ve Dünya Aile Hekimleri Birliği (WONCA) beraber ortaya koydukları 'Birincil Bakımda Ruh Sağlığı Bildirgesi’nde, tüm toplumlarda sıklığ1 giderek artan ruhsal hastalıkların olabildiğince erken evrede ve sistematik bir yaklaşımla, kişinin evine ve toplumuna yakın bir ortamda tedavisinin en iyi sonucu doğuracağı vurgulanmıştır. ${ }^{2}$ Şüphesiz birinci basamak hekimliği açısından, bu rahatsızlıklar arasında en önemli hastalık depresyondur. Depresyonu olan hastaların \%6075'i, yakınmaları için psikiyatristler yerine, ilk önce bir birinci basamak hekimine başvurmaktadır. ${ }^{3}$ Aşağıdaki derlemede, özellikle hayali bir vaka aracılığı ile birinci basamakta depresyon tanısı, tedavisi ve takibi konusunda güncel bilgilerin gözden geçirilmesi amaçlanmıştır.

\section{VAKA (Bölüm 1)}

"Dr. Mehmet Bey, içeriye giren bir sonraki hastasını gördüğünde içinden karamsar düşünceler geçti. Funda Hanım, 59 yaşında idi ve kendisine dokuz ay önce kayıt yaptırmıştı. O zamandan bu yana, yaklaşı iki veya üç ayda bir sürekli, geçmeyen baş ă̆rları şikâyeti ile kendisine gelmekte idi. Birçok medikal tedavi çeşidi denemesine ră̆men, baş ăgrllarl konusunda sonuç alamayınca, hastasının da ısrarı ile Funda Hanımı il devlet hastanesinde bir nöroloğa göndermişti. Burada, kendisine bilgisayarl tomografi gibi görüntüleme yöntemleri de dahil çeşitli incelemeler gerçekleştirilmişti, ancak baş ă̆rısına neden olabilecek herhangi bir soruna rastlanmamıştı. Dr. Mehmet Bey hastasına, onu aile să̆lı̆̆ merkezine tekrar getiren şikâyetinin ne olduğunu sorduğunda, Funda Hanım cansiz, bezgin ve enerjisiz bir ses tonu ile baş ağrıları için ilaç yazdırmaya geldiğini söyledi."

\section{Tanım ve Epidemiyoloji}

Depresyon, belirli bir nedeni olmadan bireyin kendini sürekli üzüntülü, melankolik veya kederli hissetmesi, bu duruma yoğun bir bunalt1, değersizlik, güçsüzlük, isteksizlik, olumsuz bir bakış açısı gibi duyguların eşlik ettiği, ayrıca beraberinde düşünce, konuşma, devinim ve bazı fizyolojik işlevlerde yavaşlamanın gözlendiği bir duygu durum (mood) bozukluğudur. ${ }^{4}$ Özetle, bireydeki duygusal, davranışsal, bilişsel ve somatik regülasyonu etkileyen karmaşık bir sendromdur. Depresyona pek çok psikiyatrik veya psikiyatrik olmayan hastalıklar eşlik edebilir ve yaşamının ilk alt1 ayından sonuna kadar herhangi bir zamanda izlenebilir. ${ }^{5}$ Eğer hastada bağımlılık yapıcı madde kullanımı veya depresyonla ilişkilendirilebilecek başka bir hastalık yoksa, bu durum birincil duygu durum bozuklukları olarak adlandırılır. Birincil duygu durum bozuklukları, depresif (unipolar) ve manik depresif (bipolar) olarak temelde ikiye ayrılır. Unipolar duygu durum bozuklukları ise, majör depresyon, inatçı depresif bozukluk ve başka türlü sınıflandırılmamış depresyon olarak sınıflandırılmaktadır.

DSÖ 1990 yılında unipolar majör depresyonu, dünyada en s1k izlenen beşinci önemli sağlık sorunu olduğunu bildirirken, 2020 yılında iskemik kalp hastalıklarından sonra en önemli ikinci sağlık sorunu olacağını tahmin etmektedir. ${ }^{6}$ Depresyonun gerek DALY (Disability Adjusted Life Year / İşlev Kaybına Uyarlanmış Yaşam Y1lı), gerekse de ADL (Activities of Daily Living / Günlük Yaşamsal Faaliyetler) ve yaşam kalitesi ölçümleri bazında insan yaşamında ve işlevlerinde pek çok hastalıktan (iskemik kalp hastalığı, serebrovasküler olaylardan v.b.) çok daha fazla kayba yol açtığı düşünülmektedir. ${ }^{7}$

Dünya üzerinde depresyon, birinci basamakta en sık görülen psikiyatrik hastalıktır. Kadınların \%20'sinde, erkeklerinde \%10'unda, yaşamlarının bir döneminde depresyon görülür. ${ }^{8}$ Yapılan geniş epidemiyolojik çalışmaların verilerine göre, yaşam boyu prevalans \%4,9 ile $\% 17,1$ arası değişmektedir. ${ }^{9}$ Weismann ve arkadaşlarının yaptığı ECA (Epidemiologic Catchment Area) çalışması verilerine göre, yıllık unipolar majör depresyon prevalansı \%2,6 - \%6,2 arasıdır. ${ }^{10}$ Ülkemizde yapılan bazı çalışmalarda depresyon yaygınlığ 1 , genel nüfusta $\% 14$ - 25, yaşlilarda ise \%29 (erkeklerde \%24, kadınlarda \%33) olarak bildirilmiştir. ${ }^{11-15}$ Türkiye Ruh Sağll̆̆ Profili çalışmasında ise, 12 aylık unipolar depresif epizot sıklı̆̆1 yaygınlığı kadınlarda \%5,4, erkeklerde $\% 2,3$, tüm nüfusta $\% \quad 4$ olarak bulunmuştur. ${ }^{16}$

\section{VAKA (Bölüm 2)}

“Dr. Mehmet Bey, Funda Hanım'ı dinlerken bir yandan da onunla ilgili bildiklerini akllından geçirdi. Funda Hanım'ın eşi, bir yıl önce takip edildiği akciğer kanseri nedeniyle başka bir ilde ölmüştü. Eşi öldükten sonra, daha önce yaşadı̆̆ şehirden ayrlmış ve buraya ikinci bebeğini yeni doğurmuş olan kızının yanına taşınmıştı. Bebeğin bakımındaki ana sorumluluğu kendisi üzerine almıştı. Funda Hanım bu kez uykusuzluktan çok şikâyetçi olduğunu anlatıyordu. Özellikle yattıktan sonra uykuya dalamıyor ve sürekli gece boyunca uyanıyordu. Hayattan zevk alamadığını ve baş 
fizyopatolojide etkindir. Özellikle postsinaptik transmitter miktarının artırılması ile semptomlar düzelmektedir. Adrenal, tiroid ve büyüme hormonu eksenleri depresyonda rol oynayan başlıca nöroendokrin mekanizmalardır. ${ }^{19}$

Yapılan çalışmalarda, depresyon için bazı kişilerin sosyodemografik ve klinik özelliklerinin risk oluşturduğu gösterilmiştir. ${ }^{20}$ Kadınlar arasında,

düşük sosyoekonomik düzeyi olanlarda, stresli yaşam olayları yaşayanlarda, aile veya arkadaş çevresinin kaybı halinde, depresyon veya intihar açısından aile hikâyesi olanlarda depresyon s1k izlenmektedir. Daha önce intihar girişimi hikâyesi olanlarda, postpartum dönemde, herhangi bağımlılık yapıcı madde kullanımı varsa ve eşlik eden anksiyete gibi diğer bir psikiyatrik hastalık varlığında depresyon açısından uyanık olunmalıdır. Erkeklerde 55 yaşından sonra, kadınlarda ise 35-45 yaşlarından sonra daha sık izlenmektedir. Bazı hastalıkların varlığında özellikle depresyon sık izlenebilir. bu durumda altta yatan komorbidite çözülmeden, depresyon etkin bir şekilde çözülemez. İkincil olarak duygu durum bozukluğu yapabilecek hastalıklar ve durumlar Tablo 2'de gösterilmiştir.

\begin{tabular}{|l|l|}
\hline \multicolumn{2}{|c|}{ Tablo 2. İkincil unipolar duygu durum bozukluğu seb } \\
\hline Beslenme yetersizlikleri & Endokrin hastalıklar \\
Vit B 12, folat, demir, tiamin, & Hiper/hipotiroidizm \\
niasin eksikliği & Diabetes mellitus \\
Romatolojik hastalıklar & Hiperkalsemi \\
Sistemik lupus eritematozus & Menopoz \\
Romatoid artrit & Nörolojik hastalıklar \\
Sarkoidoz & İne \\
Kardiyak hastalıklar & Alzheimer \\
Mitral valv prolapsusu & Huntington hastalı̆̆ı \\
Miyokard enfarktürü & Multiple skleroz \\
Hipertansiyon & Kontrolsüz epilepsi \\
Gastrointestinal hastalıklar & Parkinson \\
Siroz & Migren \\
Pankreatit & Dermatolojik hastalıklar \\
Enflamatuvar bağırsak & Psöriasis \\
hastalıkları & Saç dökülmesi \\
Hematolojik hastalıklar & Renal hastalıklar \\
Orak hücreli anemi & Üremi \\
Hemofili & Kronik Böbrek Yetmezliği \\
& \\
\hline
\end{tabular}

\section{VAKA (Bölüm 3)}

"Dr. Mehmet Bey, sorgusunu derinleştirdiğinde Funda Hanım'ın uzun zamandır hayattan hiç zevk almadı̆̆ını, gündüz zamanının büyük kısmını torununa bakarak geçirdiğini, şu an torununa bakmaktan başka hiçbir şeyin kendisine zevk vermediğini, ama çoğu zaman kolunu bile kaldıracak gücü bulamadı̆̆ını öğrendi. Funda Hanım kilo vermeye çalışmamasına rağmen, son dönemde 7 veya 8 kilo verdiğini anlattr. Eskiden resim yapmaktan ve resim dersi vermekten çok hoşlandiğın,l ama taşındıktan sonra resim yapmak için gerekli eşyaları kolilerden bile çıkartmak için bir neden bulamadığını belirtti. “

\section{Depresyon Tarama ve Tanı Testleri}

Birinci basamakta depresyonun rutin olarak taranması konusunda farklı görüşler mevcuttur. USPSTF (U.S. Preventive Services Task Force / Birleşik Devletler Koruyucu Hizmetler Görev Gücü) tüm adölesanlar (12-18 yaş arası) ve erişkinlerde ( $>18$ yaş) hasta tanı, tedavisi ve takibi için multidisipliner (Psikiyatrist, psikolog, terapist

Enfeksiyoz hastalıklar
Hepatit
İnfluenza
İnfeksiyoz mononükleoz
Tüberküloz
AIDS
Neoplastik hastalıklar
Pankreas ca
Lenfoma
Lösemi
Akciğer ca va toksinler
Madde ve
Barbitürat, benzodiazepin, simetidin,
betabloker, steroid, indometazin, alfa-
metildopa, oral kontraseptif, sülfonamid,
kokain, dijitaller

vb.) bir hizmet sunumu sağlayan kurumlarda tüm bireylerin depresyon açısından taranması gerektiğini belirtmektedir. ${ }^{21}$ USPSTF, özellikle tarama yaparken hastalara DSM-V TR tan kriterlerinde de vurgulanan iki kritik sorunun öneminin altını çizmiştir. Bunlar "Son iki haftadır kendini nedensiz yere mutsuz hissediyor musunuz?" ve "Eskiden yapmaktan zevk aldığınız ve ilgi duyduğunuz şeylere karşı son iki haftadır ilginizde azalma oldu mu?" sorularıdır. Bu iki sorudan birisine bile evet diyen bir bireye uygulanacak daha uzun bir tanı ve /veya tarama testi, belirgin şekilde depresyon lehinde anlamlı sonuç vermektedir. Farklı yaş ve hastalar için değişik depresyon tarama ve tanı testleri mevcuttur. $^{22} \mathrm{Bu}$ testlerin güvenilirlikleri yüksek iken (\%80-90), duyarlılıkları daha ortalama düzeydedir (\%70-80). Bu testler, hastanın kendi kendine veya bir hekim eşliğinde yüz yüze uygulananlar olarak ikiye ayrılırlar. Ülkemizde, hastanın kendi kendine uyguladıkları ölçekler arasında, Beck Depresyon Envanteri (BDE) ve Zung Depresyon Anketi sayllabilir. ${ }^{23}$ Hekimin, hastasına yüz yüze uyguladıkları arasında, Hamilton Depresyon Derecelendirme Ölçeği, Montgomery-Asberg Depresyon Derecelendirme 
Ölçeği örnek gösterilebilir. Belirli yaş grupları için geliştirilmiş depresyon ölçekleri arasında ise Çocuklar İçin Depresyon Ölçeği, Geriatrik Depresyon Ölçeği bulunmaktadır. Calgary şizofrenide depresyon ölçeği, Cornell demansta depresyon ölçeği ve Edinburgh doğum sonras1 depresyon ölçeği gibi belli tıbbi duruma sahip kişiler içinde geliştirilmiş ölçeklerde mevcuttur.

\section{Vaka (Bölüm 4)}

“Dr. Mehmet Bey, Funda Hanım'ın yakın zamanda yapılan laboratuvar tetkiklerini tekrar gözden geçirirken, sistematik bir şekilde bazl sorular yöneltti. Funda Hanım devlet hastanesine sevk edildiğ zaman yapılan tam kan sayımı incelenmesi, kan biyokimyast ve tam idrar tahlili değerleri normaldi. Funda Hanım'ın şu an için düzensiz

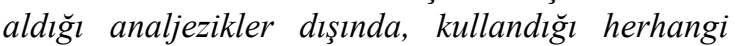
başka bir

ilaç yoktu. Dr. Mehmet Bey, en kısa zamanda Funda

Hanım'dan bir tiroit fonksiyon testi isteyebileceğini düşündü ve doldurmasını rica ederek bir BDE verdi."

\section{Konsültasyon veya Sevk Kriterleri}

Birinci basamak hekiminin, depresyon tanısı alan bir hastası olduğunda ilk yapması gereken, hastanın başka bir merkeze sevk edilip edilmeyeceğine karar verilmesidir. $\mathrm{Bu}$ açıdan, depresyon hastasının intihar riskini değerlendirmek hayati önem taşımaktadır. Hastada intihar düşüncesi ve bununla ilgili herhangi bir plan varlığında, hasta vakit geçirilmeden ciddi psikiyatrik yardım sunan bir merkeze yönlendirilmelidir. İntihar girişimi ve tamamlanmış intihar girişimi için risk faktörleri Tablo 3'te sunulmuştur. Hastanın günlük işlevselliğinde ciddi azalma, günlük işlevleri etkileyecek düzeyde eşlik eden bilişsel bozukluk, psikotik semptom, bağımlılık yapıcı madde kullanımı, daha öncesinde bipolar hastalık hikayesi ve / veya ciddi başka bir psikiyatrik bozukluk varlığında hasta bir psikiyatriste zaman kaybedilmeden sevk edilmelidir. ${ }^{25}$ Ayrica etkin dozda ve sürede en az iki tedavi denemesine karşılık hasta semptomlarında değişiklik olmuyor veya istenen düzeyde değilse hasta Elektrokonvülziv tedavi (EKT) açısından değerlendirilmek üzere yine bir psikiyatriste sevk edilebilir. ${ }^{26}$

\begin{tabular}{|c|c|}
\hline Girişim* & Tamamlamış Girişim $^{\ddagger}$ \\
\hline Kadın cinsiyeti & Erkek cinsiyeti \\
\hline Yaş $<30$ y1l & Yaş> 55 y1l \\
\hline Tek başına yaşama & Beraberinde kronik bir hastalık (Kanser, Diyabet vb.) \\
\hline Eşlik eden ciddi psikososyal stres (İş kaybı, ayrılık) & Sosyal izolasyon (Boşanmış, dul) \\
\hline Madde kullanımı (alkol, esrar vb.) & Ailede intihar hikâyesi \\
\hline Eşlik eden bir kişilik bozukluğu & Madde kullanımı (alkol, esrar vb.) \\
\hline Depresyon & Depresyon veya depresyon için aile hikayesi \\
\hline
\end{tabular}

\section{Vaka (Bölüm 5)}

"Funda Hanim envanterden toplam 41 puan alıyordu. Bu puana göre Dr. Mehmet Bey, Funda Hanım'ın şiddetli depresif belirtiler gösterdiğini anladi. Funda Hanım'ın diğer belirtilerini de değerlendiren Dr. Mehmet Bey, hastasındaki yas reaksiyonun normale göre çok uzun sürdüğ̈̈nü ve bipolar majör depresyon atağ geçirdiğini düşündü. Dr. Mehmet Bey, Funda Hanıma hiç canına klymayı düşünüp, düşünmediğini ve bunun için bir tasarısı olup olmadı̆̆ını sordu. Funda Hanım ağlamaya başlayarak, kızının ve torununun kendisine ihtiyacr olduğunu ve böyle bir şeyi düşünmediğini, ama hayatın ona çok boş geldiğini anlatt. Funda Hanım'a, eşine kanser teşhisi konduktan beş yıl önce, adını bilmediği bir depresyon ilacı başlanmıştı ve ilacı altı ay kadar kullanmıştı. Kendi ifadesi ile ilaçtan oldukça yarar görmüşü. Dr. Mehmet Bey, hastasına şu anki klinik durumu ile ilgili bilgi verdi ve Seçici Serotonin Gerialım Inhibitörleri (SSRI) grubu bir antidepressan ilaç kullanmasını önerdi. Bir hafta sonrasina randevu verdi ve mümkünse bu randevuda Funda Hanım'ın kızıyla da konuşmak istediğini belirtti.

\section{Tedavi}

Depresyon tedavisi bireysel olmalıdır. En başarılı tedavi sonuçları, biyopsikososyal yaklaşımla planlanan terapilerden elde edilebilir. Farmakolojik tedavinin yanı sıra, sosyal çevre desteği ve psikoterapi çok başarılı sonuç verebilir. Tedavinin ilk basamağında, hastanın özelliklerine göre tercih edilen bir antidepresif ilaç, en az üç haftası etkin, tolere edilen en üst dozdan, ortalama altı haftalık bir süre için kullanılmalıdır. Bu süreden sonra, tedavi sonuçları değerlendirilerek gerekiyorsa başka 
bir alternatif ilaca geçilebilir. Hastanın daha önceden kullandığg ve yarar gördüğü bir ilaç varsa ilk tercih olarak seçilmelidir. ${ }^{20,24}$

Farmakoterapinin etkinliği, kişinin sosyal ve hastalık özellikleri ile değişmektedir. Erken tedaviye başlandığ 1 , distimik veya depresyon sürelerinin kısa olduğu durumlarda, başta psikoz olmak üzere kişinin ilave bir psikiyatrik hastalığının olmadığı hallerde, alkol veya başka bağımlılık yapıcı madde kullanımı yoksa farmakoterapi çok daha etkin sonuçlar vermektedir. Ayrıca, kişinin hastalık öncesi sosyal aktivitelerinin yeterli düzeyde olması, başta aile olmak üzere sosyal ve iş çevresinden yeterli destek gördüğü hallerde, olumsuz hayat olaylarının s1klığı ve şiddetinin belirli bir düzeyde kaldığ başarılı olmaktadır. ${ }^{1}$

Hamile ve emziren kadınlarda B kategorisindeki (FDA) antidepresanlar verilebilir (Sertralin). Gebeliğin ilk 3 ayında tek seçenek EKT'dir. EKT, yine, yaşlılarda major depresyonda etkinliği bilinen ve en sık kullanılan tedavi seçeneklerinden biridir. ${ }^{27,28}$

Tedaviden istenilen düzeyde fayda sağlanamıyorsa, ilaç dozları tedricen arttırılarak gerektiğinde en yüksek tedavi dozuna yükseltilmelidir. Hastada iyileşme sağlandıktan sonra, tedaviye aynı dozda 6 ay-1 y1l daha devam edilmelidir. Bazı hallerde, sı tekrarlayan depresyon atakları olan hastalarda fayda sağlayan ilaca ömür boyu devam edilmesi önerilmektedir. ${ }^{29,30}$

Depresyon tedavisinde kullanılan ilaçlar Tablo 4'de gösterilmiştir. Birinci basamakta, günümüzde gelişmiş güvenlik ve tolerabilite özellikleri sebebiyle, SSRI ve serotonin noradrenalin gerialım inhibitörleri (SNRI) daha sıklıkla kullanılmaktadır. Monoamin oksidaz (MAO) inhibitörleri ve trisiklik antidepresanlar (TCA) artık çok daha az miktarda tercih edilmektedir. Antidepresan ilaç tedavisi sırasında alkol alınması önerilmemektedir. ${ }^{31}$

Bunların dışında; bilişsel terapi, davranışsal terapi, hipnoterapi gibi psikolojik yaklaşımların, alkol ve/ veya sigara gibi kötü alışkanlıkların terkinin, egzersiz, fototerapi/ akupunktur gibi tamamlayıcı yaklaşımların ve bazı bitkisel tavsiyelerin (sarı kantaron otu, ginko biloba) hafif ve orta düzeyde depresyonda etkili olduğu gösterilmiştir. ${ }^{32-38}$

\section{Vaka (Bölüm 6)}

"Dr. Mehmet Bey, SSRI grubu bir anti depresan başladığı Funda Hanım' i iki ay sonra gördügüüde, başlangıçtaki belirtilerin oldukça gerilediğini fark etti. Ilaç tedavisine başlayalı altı kez görüşmüşlerdi ve bu görüşmelerde Funda Hanım giderek daha az baş ağrllarından bahsetmişti. Funda Hanım, çok daha iyi uyuduğunu belirtirken, Dr. Mehmet Bey, hastasinin sesine enerji geldiğini fark etti. Funda Hanım, kızının başı sıkıştı̆̆ında torununun bakımına destek oluyordu, ama bu konudaki ana sorumluluğu kızına ve yeni bakıcıya bırakmıştı. Funda Hanım, tekrar resim yapmayı düşündügünü ve hatta ileride bu konuda ögrencilere kurs vermeyi düşündügünü anlattı. Dr. Mehmet Bey, BDE'yi tekrarladığında Funda Hanım'ın envanterden 12 puan aldığını gördü. Funda Hanım'ın, tedavinin ne kadar süreceğini sorması üzerine, en az dört ay daha aynı şekilde ilacı kullanmasını önerdi.

\section{İzlem}

Bir depresyon hastasının, ortalama izlem süresi 6 ile 12 ay arası değişebilir. Farmakoterapi başlandıktan sonraki ilk haftada, özellikle ağır majör depresyon hastalarında intihar olasılığ 1 arttı̆̆ unutulmamalıdır. Bu nedenle, bu tarz bir girişimde bulunacağı konusunda en ufak bir şüphe bulunan hastalar yakın takibe alınmalıdır. Yeni tedavi başlanmış hastaların, ilk ay içinde haftada bir takip esnasında bir iki ayda bir gözlenmesi çok yararlıdır. Tedavinin etkinliğini değerlendirmek için, birinci basamak hekimi tarama veya tanı koyma esnasında kullanılan depresyon değerlendirme ölçeklerinden birini takipte kullanmalıdır. Tercih edilen anketin, başlangıç değerlenmesindeki skorunda $\% 50$ ve üzeri bir düzelme tedaviye yanıtı gösterir. Her ölçek için tanımlanmış belli skor değerine inilmesi, hastada remisyona ulaşıldığını (düzelmeyi) göstermektedir. ${ }^{39}$

Tedaviye direnç ve nüks depresyon tedavisinde önemli bir sorundur. Bu durumlarda, bir psikiyatristten konsültasyon istemek veya hastayı başka bir merkeze yönlendirmek gerekebilir. Barkow ve ark., 12 aylık izlem sonunda, birinci basamakta tedavi edilen hastaların \%33,5'inde depresyonun devam ettiğini görmüşlerdir. ${ }^{40}$ Yapılandırılmış ve kısa (<beş dakika) telefon konsültasyonlarının hasta izlemlerinde etkili olduğu bilinmektedir. Simon ve ark. tarafindan gerçekleştirilen bir çalışmada, anti depresif tedavi başlandıktan sonraki 8 . ve 16 . haftalarda yapılan 10-15 dakikalık iki telefon görüşmesinden sonra, ayaktan izlenenlere kıyaslandığında telefonla görüşülen hastaların, ilaç uyumlarının daha iyi olduğu ve depresif belirtilerinde $\% 50$ azalma olduğu saptanmıştır. ${ }^{41}$ 


\begin{tabular}{|c|c|c|c|}
\hline $\begin{array}{l}\text { Sinıf, } \\
\text { Mekanizması }\end{array}$ & Yan Etki & Doz & Not \\
\hline \multirow{6}{*}{$\begin{array}{l}\text { SSRI } \\
\text { Seçici Serotonin geri } \\
\text { alımı inhibisyonu }\end{array}$} & \multirow{6}{*}{$\begin{array}{l}\text { Bulantı, kusma ishal, baş ağrısı, tremor, } \\
\text { sedasyon, ağız kuruluğu, cinsel yan etkiler } \\
\text { (cinsel isteksizlik, empotans, geç boşalma v.b.) }\end{array}$} & Sitalopram 20-60 mg & \\
\hline & & Essitalopram 10-30 mg & İlaç etkileşimi az \\
\hline & & Fluoksetin $20-80 \mathrm{mg}$ & Uzun Yarı Ömür \\
\hline & & $\begin{array}{ll}\text { Fluvoksamin } & 100-300 \\
\text { mg } & \end{array}$ & \\
\hline & & Paroksetin 20-60 mg & $\begin{array}{lr}\text { Kilo } & \text { alımı } \\
\text { problemleri } & \text { s1k } \\
\text { izleniyor } & \end{array}$ \\
\hline & & Sertralin 50-200 mg & \\
\hline \multirow{3}{*}{$\begin{array}{l}\text { SNRI } \\
\text { Seratonin ve } \\
\text { noradrenalin geri alımı } \\
\text { inhibisyonu }\end{array}$} & \multirow{3}{*}{$\begin{array}{l}\text { Bulantı, kusma, ishal, baş ağrısı, tremor, ağız } \\
\text { kuruluğu, cinsel yan etkiler ( cinsel isteksizlik, } \\
\text { empotans, geç boşalma v.b.) }\end{array}$} & Venflaksin 75-225 mg & $\begin{array}{ll}\text { Kan } & \text { basınc1 } \\
\text { yüksekliği } & \\
\end{array}$ \\
\hline & & Duloksetin $60 \mathrm{mg}$ & \\
\hline & & Milnasipran 50-100 mg & $\begin{array}{l}\text { Asıl atılım yolu } \\
\text { böbrekler } \\
\text { olduğundan böbrek } \\
\text { yetmezliklerinde } \\
\text { dikkatli } \\
\text { kullanılmalıdır. }\end{array}$ \\
\hline $\begin{array}{l}\text { NRI } \\
\text { Noradrenalin geri } \\
\text { alınım inhibisyonu }\end{array}$ & $\begin{array}{l}\text { Ağı kuruluğu, konstipasyon, tremor, bulanık } \\
\text { görme, taşikardi, idrar retansiyonu }\end{array}$ & Reboksetin 4-8 mg & \\
\hline $\begin{array}{l}\text { NDRI } \\
\text { Noradrenalin ve } \\
\text { ddopamin geri alınım } \\
\text { inhibisyonu }\end{array}$ & $\begin{array}{l}\text { Ağız kuruluğu, konstipasyon, tremor, bulanık } \\
\text { görme, konvülziv atak geçirme riski }\end{array}$ & Bupropion $150-300 \mathrm{mg}$ & $\begin{array}{l}\text { Daha az cinsel yan } \\
\text { etki izlenir }\end{array}$ \\
\hline $\begin{array}{l}\text { NaSSA } \\
\text { Noradrenalinerjik ve } \\
\text { spesifik serotonerjik } \\
\text { etki, } \alpha 2 \text { antogonizma }\end{array}$ & Uyuklama, aşırı kilo alımı & Mirtazapin 15-45 mg & $\begin{array}{lr}\text { Uyku } & \text { problemi } \\
\text { olanlarda } & \text { tercih } \\
\text { edilebilir. } & \text { Cinsel } \\
\text { yan etki az } & \end{array}$ \\
\hline $\begin{array}{l}\text { SARI } \\
\text { Seratonin } \\
\text { antagonizmas1/ geri } \\
\text { alım inhibisyonu }\end{array}$ & Aşırı sedasyon, nadir priyapizm & Trazodon 50-300 mg & $\begin{array}{lr}\begin{array}{l}\text { Uyku } \\
\text { olanlarda } \\
\text { edilebilir }\end{array} & \text { problemi } \\
& \end{array}$ \\
\hline \multirow[t]{3}{*}{$\begin{array}{lr}\text { TCA } & \\
\text { Serotonin } & \text { ve } \\
\text { noradrenalin } & \text { geri } \\
\text { alınım inhibisyonu } & \end{array}$} & \multirow{3}{*}{ 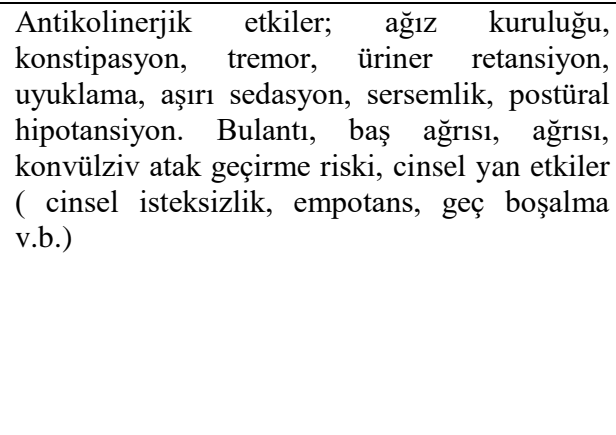 } & Amitriptilin $75-300 \mathrm{mg}$ & $\begin{array}{lr}\text { Uyku } & \text { problemi } \\
\text { olanlarda } & \text { tercih } \\
\text { edilebilir. } & \end{array}$ \\
\hline & & $\begin{array}{l}\text { Klomipramin } 75-300 \\
\text { mg }\end{array}$ & OKB'de etkilidir \\
\hline & & Maprotilin 25-150 mg & $\begin{array}{lr}\text { Konvülziv } & \text { atak } \\
\text { eşiğini } & \text { çok } \\
\text { azaltmaktadır } & \end{array}$ \\
\hline $\begin{array}{l}\text { MAO İnhibitörleri } \\
\text { Serotonin, noradrenalin } \\
\text { ve dopamin yıkımı } \\
\text { inhibisyonu }\end{array}$ & & $\begin{array}{l}\text { Moklobemid } 300-600 \\
\text { mg }\end{array}$ & \\
\hline
\end{tabular}

\section{SONUÇ}

Ülkemizde, 2008 yılından bu yana reçetelenen antidepresan ilaçların, yarısından fazlası birinci basamak hekimlerince yazılmaktadır. Birinci basamak hekimliği için, en önemli psikiyatrik 
rahatsızlık olan depresyon konusunda, aile hekimlerinin bilgi ve becerisinin yeterli olmasının önemi aşikârdır. Örnek vermek gerekirse, İsveç’te birinci basamakta çalışan hekimlere yapılandırılmış, depresyonun tanı ve tedavisi konusunda bir eğitim verilmesiyle, genel nüfusta depresyon sıklığında ve ortalama intihar sayısında belirgin bir azalma tespit edilmiştir. ${ }^{42}$ Yıldırım ve ark., yaptığ 1 bir çalışmada ise aile hekimlerinin $\% 19,2$ 'si kendilerini depresyon tan1, tedavi ve izlem konusunda yetersiz bulduklarını belirtmişlerdir. Aynı çalışmada, ilk kez depresyon tanısı koydukları hastalarına \%54,2'sine kendilerinin tedavi başladığ1, \%20,0'ine tedavi başlamadan psikiyatriste yönlendirdikleri ve \%25,8'ine kendilerinin tedavi başlayıp, kontrole psikiyatriste yönlendirdikleri görülmektedir. Kendilerine verilen eğitimin, yeterli olmadığını düşünen aile hekimlerinin oranı ise $\% 72,7$ gibi dikkat çekici bir değerdir. ${ }^{43}$ Birinci basamakta çalışan hekimlerin, depresyon konusunda bilgi ve becerilerini arttıracak eğitim programlarının bu konudaki hekimlerimizin etkinliğini daha da arttıracağı düşünülebilir.

\section{TEŞEKKÜR}

Yazının hazırlanma sürecindeki desteklerinden ötürü, Sn. Psikiyatrist Hilal Yılmaz'a teşekkürlerimizi iletiyoruz.

\section{KAYNAKLAR}

1. Tezvaran Z, Akan H, İzbırak G. Birinci basamak sağlık hizmetinde depresyon yönetimi. Turkish Family Physician 2010; $1(3): 1-7$.

2. Intergrating Mental Health into Primary Care: A Global Perspective. http://www.who.int/mental_health/.../mentalhe altintoprimarycare/.../index.html Erişim tarihi: 15.11.2012

3. Goldman LS, Nielsen NH, Champion HC. Awareness, diagnosis, and treatment of depression. J Gen Int Med 1999; 14: 569-80.

4. DSM-V-TR. Tanı Ölçütleri Başvuru Kitabı. (Edi. Köroğlu E.). Birinci Baskı HYB Yayınları İstanbul 2013; s. 194-97.

5. Rihmer Z, Angst J. Mood disorders: epidemiology. In: Sadock BJand Sadock VA (eds) Kaplan and Sadock's Comprehensive Textbook of Psychiatry. 7. Baskı, Philadelphia: Lippincott Williams \& Wilkins, 2005, s 44759.

6. Michaud CM, Murray CJL, Bloom PB. Burden of disease-1mplications for future research. JAMA, 2001; 285(5):535-9.

7. WHO. The World report: Solving mental health problems: principles of care. http://www.who.int/whr/2001/chapter3/en/inde x1.html Erişim tarihi: 10.2.2010
8. Kessler RC, Berglund P, Demler O, Jin R, Koretz D, Merikangas KR ve ark. National comorbidity survey replication. the epidemiology of major depressive disorder: results from the national comorbidity survey replication (NCS-R). JAMA 2003; 18; 289 (23): 3095-105.

9. Korf VM. Improving depression care. J Fam Prac 2001;50(6): 529-32.

10. Weissman MM, Bruce LM, Leaf PJ. Affective disorders in psychiatric disorders in America: the epidemiologic catchment area study. Edited by Robins LN, Regier DA. New York, Free Press, 1991, 53-80.

11. Kirpinar I, Gozum S, Pasinlioglu $\mathrm{T}$. Prospective study of postpartum depression in eastern Turkey prevalence, socio-demographic and obstetric correlates, prenatal anxiety and early awareness. J Clin Nurs 2010; 19: 422-31.

12. Kırpınar İ, Tepeli İÖ, Gözüm S, Pasinlioğlu T. Erzurum il merkezinde doğum sonras1 depresyonlarının sıklık ve yaygınlığı ile DSMIV tanısal dağılımı: İleriye dönük bir çalışma. Anadolu Psikiyatri Dergisi 2012; 13: 16-23.

13. Unsal A, Tozun M, Ayranci U. Prevalence of depression among postmenopausal women and related characteristics. Climacteric 2011; 14:244-51.

14. Kitiş $Y$, Karaçam Z. Postpartum depresyon sıklığı ve etkileyen faktörler. Türkiye'de Psikiyatri 2009; 11(2): 67-74.

15. Bekaroğlu $M$, Uluutku $\mathrm{N}$, Tanriover $\mathrm{S}$, Kirpınar I. Depression in an elderly population in Turkey. Acta Psychiatr Scand 1991; 84(2): 174-8.

16. Binbay $\mathrm{T}$, Direk N, Aker $\mathrm{T}$, Akvardar $\mathrm{Y}$, Alptekin K, Cimilli C ve ark. Türkiye'de psikiyatrik epidemiyoloji: yakın zamanlı araştırmalarda temel bulgular ve gelecek için öneriler. Türk Psikiyatri Dergisi 2013;24: 1-18.

17. Barret JR. Treatment of Dsthymia and minor depression in primary care. J Fam Prac; 2001;50:(5);405-13.

18. Smith WT, Kendrick T. Diagnosing and treating depression. BMJ 2000;320: 1602-10.

19. Lam RW, Mok H. Depression. 1. Bask1, New York: Oxford University Press, 2008: 21-32.

20. Aydoğan Ü, Nerkiz P, Sarı O. Birinci basamakta sık görülen psikiyatrik bozukluklar: depresyon ve anksiyete. Türkiye Klinikleri J Fam Med-Special Topics 2012;3(2):1-7

21. U.S. Preventive Services Task Force. Depression in adults: Screening. http://www.uspreventiveservicestaskforce.org/ Page/Document/UpdateSummaryFinal/depressi on-in-adults-screening (Son Erişim Tarihi: 10.6.2015)

22. Öner N. Türkiye'de kullanılan psikolojik testler bir başvuru kaynağı. Üçüncü Baskı. Boğaziçi Üniversitesi Yayınları. İstanbul; 1997: 13-20. 
23. Kılınç S, Torun F. Türkiye'de klinikte kullanılan depresyon değerlendirme ölçekleri. Dirim T1p Gazetesi 2011; 186; 1: 39-47.

24. Yüksel N. 'Ruhsal hastalıklar. 3. Baskı MN Medikal \& Nobel. İstanbul 2006; s. 183-220.

25. Guck TP, Kavan MG, Elsasser GN, Barone EJ. Assessment and treatment of depression following mycordial infarction. Am Fam Physician 2001; 64:641-8.

26. Hickie IB, Andrews G, Davenport TA: Measuring outcomes in patients with depression or anxiety: an essential part of clinical practice. MJA 2002; 177(4): 205-7.

27. Özten E, Sayar GH. Gebelikte depresyonun somatik tedavisi. Psikiyatride Güncel Yaklaşımlar-Current Approaches in Psychiatry 2015; 7(3):244-254.

28. Topbaş E, Eroğlu MZ, Zabun S, Güneş T, Çalışkan M. Depresyon ve parkinson hastalığı birlikteliğinde elektrokonvülsif tedavi kullanımı: bir olgu sunumu. Cukurova Medical Journal 2014;39(1):185-188.

29. Keller MB, Klerman GL. Long term outcome of episodes of major depression; clinical and public health significance. JAMA, 1984; 252:788-92.

30. Arroll B, Elley CR, Fishman T, GoodyearSmith FA, Kenealy T, Blashki G. Antidepressants versus placebo for depression in primary care. Cochrane Database of Systematic Review 2009; 3:CD007954

31. Stahl SM. Stahl's essential psychopharmacology, neuroscientific basis and applications. 3. Bask1, New York: Cambridge University Press, 2008: 511-666.

32. Hensley PL, Nadiga D, Uhlenhuth EH. Longterm effectiveness of cognitive therapy in major depressive disorder. Depress Anxiety 2004;20(1):1-7.

33. Cuijpers $P$, van Straten A, Warmerdam L. Behavioral activation treatments of depression: a meta-analysis. Clin Psychol Rev 2007;27(3):318-26.

34. Alladin A, Alibhai A. Cognitive hypnotherapy for depression: an empirical investigation. Int $\mathbf{J}$ Clin Exp Hypn 2007;55(2):147-66.

35. Mead GE, Morley W, Campbel IP, Greig CA, McMurdo M, Lawlor DA. Exercise for depression (Cochrane Review). In: The Cochrane Library, Issue 4, 2008. London:Wiley. Dunn AL, Trivedi MH, O’Neal HA. Physical activity doseresponse effects on outcomes of depression and anxiety. Med Sci Sports Exerc 2001;33(Suppl 6):p587-S97.

36. Linde K, Mulrow CD, Berner M, Egger M. St John's wort for depression (Cochrane Review). In: The Cochrane Library, Issue 4, 2008. London:Wiley. p. 65.

37. Hardy M, Coulter I, Morton SC. S-adenosyl-Lmethionine for treatment of depression, osteoarthritis, and liver disease. Agency for Healthcare Research and Quality (AHRQ) guideline; 2002. Erişim http:// www.ncbi.nlm.nih.gov/bookshelf/br.fcgi?book =hserta\&pa rt=A101701 Erişim tarihi:1.5.2014

38. Schuch FB, Vancampfort D, Richards J. Exercise as a treatment for depression: A metaanalysis adjusting for publication bias. J Psychiatr Res 2016; 77:42-51

39. Bostwick JM, Pankratz VS. Affective disorders and suicide risk: a reexamination. Am J Psychiatry 2000; 157(12): 1925-32.

40. Barkow K, Maier W, Üstün TB, Gansicke M, Wittchen HU, Heun R. Risk factors for depression at 12-month follow-up in adult primary health care patients with major depression: an international prospective study. J Affect Disord 2003; 76: 157-69.

41. Simon EG, Vonkorff M, Rutter C, Wagner E: Randomise trial of monitoring, feedback, and management of care by telephone to improve treatment of depression in primary care. BMJ 2000; 320:550-4.

42. RihmerZ, Rutz W, Pihlgren H. Depression and suicide on Gotland an intensive study of all suiceds before and after a depression training programme for general practitioners. J. Affect Disor 1995;35(4):147-152.

43. Yıldırım A, Gönüllü OG, Eradamlar N, Erkıran M. İstanbul ili genelinde görev yapan aile hekimlerinin antidepresan reçetelemesini etkileyen faktörler. Düşünen Adam; The Journal of Psychiatry and Neurological Sciences 2014; 27:242-249. 